Article

\title{
Processes of Inclusion and Exclusion in the Sphere of Prosumerism
}

\section{Roberta Paltrinieri and Piergiorgio Degli Esposti *}

Department of Sociology and Business Law, Bologna University, Strada Maggiore, Bologna 45, Italy; E-Mail: roberta.paltrinieri@unibo.it

* Author to whom correspondence should be addressed; E-Mail: piergiorgio.degliesposti@unibo.it; Tel.: +39-051-2092-882; Fax: +39-051-2092-906.

Received: 10 December 2012; in revised form: 21 December 2012 / Accepted: 6 January 2013 / Published: 10 January 2013

\begin{abstract}
The term prosumer, first introduced by Toffler in the 1980s, has been developed by sociologists in response to Web 2.0 (the set of technologies that has transformed a predominantly static web into the collaborative medium initially envisaged by Tim Berners-Lee). The phenomena is now understood as a process involving the creation of meanings on the part of the consumer, who re-appropriates spaces that were dominated by institutionalized production, and this extends to the exploitation of consumer creativity on the production side. Recent consumption literature can be re-interpreted through the prosumer lens in order to understand whether prosumers are more creative or alienated in their activities. The peculiar typology of prosumption introduced by Web 2.0 leads us to analyze social capital as a key element in value creation, and to investigate its different online and offline forms. Our analysis then discusses the digital divide and critical consumerism as forms of empowerment impairment.
\end{abstract}

Keywords: prosumer; consumption; social capital; capitalism; consumerism

\section{Introduction}

Prosumerism has recently become a central theme in consumer theory, in that discussions relating to consumers invariably invoke the process of prosumerism.

Alvin Toffler [1] introduced the term prosumer in 1980, initially to describe a proactive consumer who is active in the design and improvement of goods and services; however, the term has subsequently evolved to describe a consumer who consumes what he produces, and this in multiple forms, which may or may not involve brands or the market. 
With this neologism, he intended to signal the emergence of a new stage - the third wave-in the relationships between production and consumption, areas that can no longer be distinguished in the distinct way achieved by industrial society.

In other words, prosumerism does not clearly define a role, a function of the consumer, but rather a process that expresses itself along a continuum that now has become, in the prosumer capitalism society [2], a circular process that induces opposing dynamics.

From this point of view, the term prosumer describes someone who, in uniting the production and consumption practices, takes possession of the meaning of content, as well as someone who lives through the process of alienation that is being gradually displaced from the sphere of work into everyday life.

The phenomena that this category embraces ranges from the enlargement of areas of creation of meanings on the part of the consumer, who retakes possession (re-appropriates) of spaces that were dominated by institutionalized production, to the extension of the exploitation of consumer creativity on the production side.

Prosumerism has experienced exponential growth in tandem with the rise of social and participatory media, with unprecedented connection speeds and access availability, and online communities that have facilitated the dissemination of user-generated content.

Understanding prosumerism therefore is increasingly important in comprehending societal changes stemming from the rise of social media, and the role of the consumer as an actor in these changes. Being a prosumer today means not only being involved in the processes of production and consumption but also, and more importantly, having a civic role and function resulting from the opportunities that digital technologies and augmented reality provide.

\section{Are Prosumers Creative or Alienated?}

Since the 1960s, a lively debate has being running on the theme of The Consumer Society [3], involving a confrontation between sociologists, anthropologists and philosophers on the social significance of consumption and its implications for our lives.

The debate between "apocalyptic and integrated" [4], essentially two modes of interpretation that have been structuring themselves over time, brings into opposition those who tend to assign a margin of individual freedom to processes of consumption - a freedom which is expressed in processes of appropriation of meaning and uses of goods - and those who maintain that the consumer contributes to the process of alienation within the sphere of work.

In the modern theory of consumption, creativity and alienation represent two extremes of a continuum that encompasses different possibilities for consumer action, and degrees of freedom that are dependent on individual skills and social context.

Although the term prosumerism does not appear in all the authors' works that we cite, with the exception of Ritzer whose discussion of prosumerism is more orthodox, our aim is to demonstrate that the sociological and anthropological approach to consumption is based on the process of prosumerism, demonstrating the extent to which the category of prosumer is based on the sociology of consumption.

The dimension of consumer creativity has been debated at length within the cultural theory of consumption that arose from cultural anthropology. The anthropologists Mary Douglas [5], 
Daniel Miller [6] and Grant McCracken [7] dealt with the social significance of the process of consumption, focusing their attention on the rituals of consumption and the individual's capacity to symbolically reappropriate goods and their uses.

In particular, Daniel Miller [6] described the reappropriation of goods as a process through which mass culture becomes re-elaborated and returns personal meaning to the object. In this sense, Miller speaks of productive consumption as the capacity for creative use of the industrial product.

In the process of appropriation, it is not necessarily the physical form of the product that changes, even if this sometimes happens-do-it-yourself, or food processing used in the preparation of - but its social nature, its symbolic significance, changes in such a way that the product becomes transformed into an object of consumption.

To the traditional concept of "authenticity"-based on a process of self production in which one consumes only what one personally produces through control of the entire production process-Miller counter-proposes one based on the capacity for symbolic appropriation, on the propensity of the commodity to be detached from mass culture and to be personalized.

This is of course a process that is far from free or independent of the consumer, who in his work on the object must confront the "biography of the object", i.e., the residue of meaning sedimented within during the initial phases of the process of signification: from the moment of conception to that of its production and commercialization, particularly through the mechanism of advertising.

In agreement with the cultural dimension of consumption, the sociologist R. Silverstone [8] speaks of a real and powerful force played out in the consumer sphere. Silverstone argues that in our daily acts of consumption, we express our hopeless dependence on material, symbolic objects of mass production, and that at the same time, with the same actions, we express our freedom as creative participants in mass culture.

The transformative or creative nature of the work of appropriation carried out by the consumer depends, naturally, on the material and cultural resources they choose to make use of. In many cases, warns Silverstone, they end up accepting "the full weight of the public meaning" inherent in the goods or the same commodity becomes "tamed and transformed into its symbolic meaning".

The ideal type of the craft consumer proposed by Colin Campbell [9] is of relevance to this theme when placed in the dimension of consumer creativity. The craft consumer is, in the words of the author, a conscious manipulator. He is an individual who uses the products he acquires with great discretion: completing them, mixing them and processing them according to very personal ends, and he does so with skill, love and passion, just like the artisans of old. The craft consumer buys items that are produced en masse and uses them as primary materials to create new ones, reinterpreting them as if they were part-works to complete, and modeling them according to subjective and creative itineraries that often have little to do with the assumptions and the project of the producer. Examples of this type range from the creative use of industrial ready-made foods as ingredients, the reworking of the mechanics of a car or a motorcycle, through to the personalization of backpacks by youngsters, and of jackets and jeans transformed into a unique mix through the use of ornamental objects.

Creativity in the production or modification of goods to be shared or passed on may also involve a social dimension that connects the creator with their local social network. In the context of the Internet, however, this social dimension may be amplified greatly, connecting the creator/modifier to a much wider social network. 
George Ritzer [10] has developed the dimension of alienation in his theory of the McDonaldization of society. Ritzer rejects what he defines as the "false modern dualism" between e-consumption and production, asserting that, even at the height of the industrial revolution, production and consumption were never completely distinct: he links the progressive relevance of the prosumption phenomenon to the process of consumer engagement in production processes.

Ritzer discusses the process of "putting the customer to work" [11], a process that has been accelerated mainly by the advent of fast food restaurants, but also by variegated forms of self-service restaurants and petrol stations, by barcode readers in supermarkets, ATMs, by the spread of self-medication tools, the finding and buying of books on Amazon, and the online purchase of train or airplane tickets.

On the one hand, it is a form of production of consumption which implies an increase in degrees of freedom for the consumer, who, by accepting his role as a prosumer, can be released from the constraints of time and space: the elimination of queues at counters and check-outs for example, or the extension of opening hours in services such as travel agencies or libraries. The consumer can now directly control a part of the production process, anticipating, in a certain sense, the moment of de-commodification, of the personalization of goods, products or services.

On the other hand, these orthodox forms of prosumerism translate into a process of overloading the consumer, associated by many with an increase in profits comparable to wage reductions during early capitalism - a new form of exploitation, attesting to capitalism's capacity to create profit through maximizing efficiency and rationalization.

SNS provide a means of communication, for users to connect and interact, which is the driver for its means of production; predominantly advertising revenue. In the SNS model, maximizing revenue is strictly correlated to maximizing communication, and therefore minimizing alienation, which could lead to less sociability and interaction within the network. Minimizing the business input costs in order to optimize efficiency - in terms of the services provided - is also strictly tied to minimizing alienation to avoid depressing communication output. The interesting aspect of the SNS model is the extent to which the consent to exploitation is proportional to creativity.

\section{Prosumption and Web 2.0}

Even though the prosumer was clearly not invented by the internet and Web 2.0, it is surely the case, as claimed by Ritzer and Jurgenson [2], that "given the massive involvement in, and popularity of, many of these developments (e.g., social networking sites), it can be argued that it is currently both the most prevalent location of prosumption and its most important facilitator as a 'means of prosumption"". The hypothesis that we are proposing is that the advent of Web 2.0 has led to the existing boundaries between the dimensions of creativity and alienation becoming increasingly ill-defined.

In the theory of cultural consumption which we cited earlier, the creativity of the consumer is realized in daily life, in the moment in which the goods leave the market and enter into networks of relationships: the process of decommodification described by Kopytoff [12].

With the advance of the networked society, the distinction between the workplace and the world of everyday life is fading away.

Digital prosumerism has, in fact, specific characteristics: 
(i) the production and sharing of content on $\mathrm{Web} 2.0$;

(ii) the abundance of produced and published content;

(iii) the unpaid work of those who produce the content; and

(iv) the online spread of a culture of free content.

Although prosumer capitalism has been theorized previously, long before the appearance of the Internet, and although the capitalist economy "has always been dominated by prosumption", Ritzer and Jurgenson [2] affirm that it is now the new frontier of capitalism, in such a way that it represents a discontinuity with the past. Primarily, it entails less control of the business activities of the prosumer, as well as greater resistance on the side of the prosumer. It is therefore a system characterized by abundance rather than scarcity, and effectiveness rather than efficiency.

The lesser control that companies have on prosumers, however, does not imply any reduction in the determination of the logic of capital; indeed, the reference is ultimately to a political economy of prosumerism in which the creativity and freedom of the consumer, linked to Web 2.0, are functional to the reproduction of capital.

Creativity and alienation can be seen as complimentary, counter to the thesis proposed earlier that viewed them as opposed along a continuum.

The Austrian sociologist Fuchs [13], in analyzing the political economy of social media, takes a position to extremes by adopting Karl Marx's value theory, and argues that prosumer production on the web is now a new means of exploitation in the creation of surplus value.

It can be argued that the reality of social media prosumption invalidates many of the basic value theory assumptions underpinning this argument, and that the exploitation is not so extreme, in that labor is compensated in other ways than wages [14]. For Fuchs, however, prosumerism in the capitalist system is an extreme form of exploitation in which the prosumer works for Capital for free: the productive time exploited involves not only the work-time of salaried employees but also time spent online by users.

A possible solution, according to Fuchs, is a political project to replace capitalism and its logic by starting with a different arrangement of relations that is no longer based on exploitation - according to the logic of social division into classes - but on the logic of sharing and participation.

Fuchs focus on commons follows on from this. Communication, which is the basis of the new arrangement, is actually a common good, as are education, environment and culture. The new outlines of a more just society would be drawn by commons based media and a commons based Internet, which would be collectively capable of facilitating commons based prosumerism in overcoming the contradictions inherent in the capitalist system.

The theme of prosumer creativity is also informed by Cova, who on rereading the discourse of marketing over the last thirty years, has come to define the contemporary discourse as collaborative marketing, in which consumers are active subjects in the co-creation of value: "Overall, collaborative marketing sees consumers as fully competent subjects in their dealings with companies, that is, as individuals who own their own resources and capacity to implement them" [15].

According to Cova, despite this creativity, the prosumer is a "governamentalized" consumer (picking up on the lesson of Foucault) because the marketing discourse creates a meta narrative of the 
Western consumer, in which the prosumer is paradoxically an autonomous co-producer, thanks to his expertise, in a system and culture of consumption by which he is shaped and controlled.

Despite obvious differences in the approaches used, and the different degrees of radicalization presented by the selected authors, the call is to not underestimate, in the macro view, the self-referential capacity of Capital to reproduce itself [16].

\section{Social Capital Online and Offline}

This capacity of the capitalist system to reproduce itself is, for the sociology of consumption, correlated to the capacity of the system of consumption to reproduce, on a structural and symbolic level, the process of social differentiation present in the wider social system $[3,17]$.

The process of differentiation is at the root of processes of inclusion and exclusion that govern relationships between individuals in society, and within relationships between social classes.

In recent years, in order to analyze these processes of inclusion and exclusion, sociology has debated the concept of social capital at some length.

For this reason the contemporary sociological debate has contributed to a growing interest in the study of social capital, together with the importance to it of "human capital", and the social relations in which the individual participates. Social capital is the opportunity that individuals have to relate to others who possess diverse experience and knowledge, so as to increase their own capital within society. The individual, who in the course of his life relates to other individuals, increases his own capacity to reach goals that would otherwise be difficult to achieve.

The French sociologist Bourdieu is credited with having developed a micro approach to social capital that theorizes it as a set of resources related to relationships that an individual maintains with the surrounding community in order to pursue his own ends and to improve his social position; hence the "individual nature" of social capital.

This approach is founded on the theory of rational choice and exchange, and considers social capital from an individual perspective as a set of resources that the actor is able to obtain from their network of social relations. Social capital can therefore be explained only in an instrumental way, as a resource for individual strategies.

In particular, Bourdieu defines social capital principally with reference to his study of social stratification: by identifying "social capital as an aggregate of actual or potential resources, which are linked to possession of a durable network of more or less institutionalized relationships of mutual acquaintance and recognition" [17]. In other words, it means inclusion in or belonging to a group that provides each of its members with credibility and support.

From this point of view, Bourdieu distinguishes a particular set of resources: those held in the relationships that individuals maintain with the surrounding community, the unequal possession of which is associated, in the process of social reproduction, with an inequality of opportunity to position themselves along the stratification of hierarchy [17]. Therefore, if one thinks of social capital in a circular manner, privileged individuals maintain their position in relation to their peers: reproducing a social stratification in which the dark side of the oppressed is dazzled by the light of the privileged, as maintained by Field [18]. 
For Bourdieu, the processes of consumption and social capital are strongly correlated because the consumer, in sociological language, is a significant factor in the process that "materializes" differentiation and reflects social positions and differences present in the social sphere [17].

Although Bourdieu does not analyze the relationship between social capital and Web 2.0, Bourdieu's instrumental view allows us to reinterpret the theory of "weak ties" [19].

In pursuing their own ends, namely to improve their social position, individuals make use of resources and personal relationships, which in their structure are capable of building trust both online and offline. For Granovetter, these resources and personal relationships constitute the strength of a bond, which he defines as weak because it is based on a combination of time, mutual trust, emotional intensity and exchange, which collectively constitute the embeddedness of economic transactions. Individuals pursue specific goals using "open social networks", in which "bridge connections" [20] link each individual to the community and other communities, and greater benefit is derived from a few contacts with persons who are weakly related to each other than from many connections with people who are well known to each other.

Nan Lin [21], in accordance with the thoughts of Bourdieu, defines social capital as resources embedded in social structure, accessed and mobilized through intentional actions: people invest in social relations in order to reap a benefit, thanks to the resources that these social relations can mobilize. The yield from social capital not only facilitates the flow of information through the recognition of the other, but it offers the possibility of exercising influence on decision makers and strengthening the identity of the individual.

Viewed in this way, prosumerism online is instrumental in the reproduction of the logic of class, and reproduces on the web the structure of differences already present in the social system. The web, in fact, cultivates in itself different cultures that have possibilities for interaction, relating to itself in symbiosis with the mainstream forms. Being connected becomes an act of daily life, breaking down the wall of access solely for the elite, while large segments of the population enter other spaces with their desires to consume and communicate. However, although the web is highly inclusive, non-hierarchical and informal - in which those who generate media content join together, no longer taking the role of the anonymous audience that gravitates around mass communication, but producers of free content to communicate with each other-there is no denying that technology introduces differences though a digital divide. The digital divide gives rise to recognizable inequalities, not only in the gap in access, but also in the knowledge necessary for the use of digital communication, in the ability to move within a digital culture, between participants, and also between and within countries. The digital divide marks, therefore, the gap between those who have effective access to digital information technology and those who are excluded, either partially or totally. The reasons for exclusion include diverse variables: economic conditions, educational level, quality of infrastructure, differences in age or sex, membership to different ethnic groups and geographic origin. In addition to the gap in actual access to technology, the digital divide also introduces disparities in the acquisition of the resources or skills necessary to participate in the information society. This gap can be identified within individual countries as well as on a global level.

The first conceptualization of the digital divide can be traced back to the early 1990s in the United States, which indicated that the possession of personal computers could represent an advantage only for some ethnic groups [22]. The concept of digital divide then entered into common usage during the 
Clinton administration to emphasize the disparity in access to e-services within the population of the United States. The "divide" started to be considered on a global scale, at the meeting of the World Economic Forum in Davos in early 2000, as an evident disparity in the distribution of technological infrastructure and communication access opportunities.

The digital divide, however, should not be addressed solely as a problem related to the level of penetration and use of communication technologies within developing countries, even if it is in these aspects that it is principally expressed. It can also be defined as a lack of opportunity to access digital technologies. This definition provides a clearer picture of the level of inequality between North and South. The digital divide, in some way, reworks the dialectic of the old divisions between North and South, between the affluent and the poor. The new frontier is between those who possess information and those who do not have access to it, between information haves and have-nots.

The digital divide therefore exhibits those differences that, in a broad sense, reproduce and amplify on the global level the structures of differences between nations, groups, and people, based on class, ethnicity, race, and gender [23-24].

Within this interpretative frame, the barriers that accentuate the division are of various types; from the concealed, such as the crucial elements that impede the introduction of a particular technology in a given context (illiteracy is undoubtedly predominant among them) to the barriers formed by the nature of infrastructure, commerce and culture.

\section{Commons Based Prosumerism}

It is a common opinion among scholars that social capital should be considered, at an individual level, as composed of two different types: bonding and bridging social capital [25]. We can identify bonding social capital as that which refers to the strong and emotional relations that are developed within the family and close friends who belong to the same peer groups. Bridging social capital describes the weak ties that are developed between people who share knowledge or new points of view, in the absence of an emotional connection [19]. Granovetter affirms that access to a new world outside the peer group can be very useful in that it allows the individual to access different feedback and new opportunities in a field of work. Nowadays, bridging social capital is perceived as an individual level, contrary to what was theorized by previous studies, which considered it as a kind of social tie linked to the concept of community $[25,26]$. For example, the way people look at themselves and how they perceive themselves as part of a broader group, and how they exhibit norms of giving within a broader community [26].

To understand this, social capital should be considered by retracing the analysis of Robert Putnam, which develops a macro approach and conceives of social capital as a collective good, consisting of shared values, social cohesion and trust [19,27].

For Putnam "social capital refers to connections among individuals - social networks and the norms of reciprocity and trustworthiness that arise from them. In this sense social capital is closely related to what some have called "civic virtue"". Putnam draws attention to the fact that civic virtue is more potent when it is incorporated in a network of reciprocal social relations, and emphasizes that a society with many virtuous but isolated individuals is not necessarily rich in social capital. In this way, Putnam recognizes the potential importance that social capital can hold for a democratic society, intending it, 
in this sense, as "connections between individuals" and as the social networks and norms of reciprocity that arise from them. Civic virtue is more powerful the more it is incorporated in a network with a sense of reciprocal social relations [25]. Central to this is the determination of cultural requirements that promote a social order characterized by general cooperation for the common good [28].

Social capital exhibits these exact requirements: the structure of relationships, values and norms that guide individuals towards such cooperation: "trust, norms that regulate living together, networks of civic associations, elements that improve the efficiency of social organization promoting initiatives taken by mutual agreement" [28], and is "closely related to the concept of civic sense" [25]. It supports ethical practices in pursuit of social order and civic engagement for social self-organization, for which every individual is able to create networks of relationships outside of their own membership group.

Social capital and civicness form a relevant characteristic of social organization by increasing the efficiency of society and by controlling opportunistic behavior in favor of collective action [28], implementing relationships of solidarity and cooperation.

An example of the commons based prosumer is given by political consumerism. Critical consumption is expressed in acts of boycott, buycott and culture jamming, which express instances of global social responsibility, giving the consumer an ethical value. For these consumer practices Web 2.0 represent social capital in that, through the production and consumption of content, online social bonds are structured that not only allow one to be recognized and distinguished as part of a community, but also allow the creation of a common horizon of solidarity.

Therefore, with augmented reality in particular, social networks sites (SNS) have relevance in discovering, maintaining and implementing social ties. Through the creation of a public or semi-public profile, a user can share a link with others and expand their number of ties through consultation with the contact lists of other users [29], which represent the relations individual users maintain within the network.

There are several recent research endeavors that have analyzed how social capital is increased and established among users, and scholars agree in recognizing the rise of new and different social relations stemming form the exchange of knowledge and information. As affirmed by several researchers - Steinfield [30], Donath and Boyd [31] among them-social network sites are the ideal place in which to develop weak ties since they provide users with all the tools necessary to maintain this kind of link. In particular, Donath and Boyd maintain that a social network, due to its intrinsic characteristics, is best suited to maintaining a wide and heterogeneous network.

The mechanisms underlying social and economic inequalities are also active for electronic citizenship, both in the political and economic power asymmetries, that severely limit access to the web, and in levels of education, making the Internet usable in a rather limited way for many individuals. The digital Internet itself however, understood as social capital, is highly inclusive: each individual can potentially reach useful information channels that facilitate the achievement of personal objectives, thereby improving the lives of individuals.

In this sense, individualized collective actions have been conceived and implemented [32] through political consumerism. The individual acts are knowledgeable and projectually designed to be interdependent. The objective being to seek out, in the sentiments and culture of solidarity, beneficial relations for sustainable consumption and development with groups and populations living in disadvantaged conditions. 
In recent years, political consumerism has greatly extended its reach beyond the well-established forms mentioned above such that, according to some researchers such as Scammell [33] and Bennett [34], it is now almost impossible to distinguish between the figures of citizen and consumer. Consumerism, intended as the individual choice of a social actor, rather than a collective public action, is currently considered as one of the most important topics of discussion within electoral policy, due to its growing relevance in the dialogue between the diverse actors in the political arena: citizens, representatives and government $[35,36]$.

Increasingly frequent campaigns to raise awareness about responsible consumption are changing public opinion and the global political landscape as they allow a direct dialogue to be established with nation states and big corporations. This revolutionary transformation has been enabled by the globalization of communication and economic organization, which has enabled individuals to make their voices heard in decision-making processes [36]. Bennett pursues his reflection on global consumer activists by emphasizing a point of great relevance: social actors are not organized in centralized structures but are networked, connected with one another, and members of active social groups. Similarly, Bennett affirms that networking is currently the foremost mechanism to share diverse opinions, connecting people with common interests but who belong to different worlds.

The Internet not only represents one of the most important and powerful mechanisms in the globalization process, it also represents a great opportunity for those who seek to organize through networks, rather than through centrally controlled associations. Social media enables this organization as it offers a concrete and personalized alternative to mass media communication. For those who have overcome the digital divide, the Internet provides an alternative mechanism for participation. Networked campaigns provide easy access and low cost of participation, and spread the collective cost across the community in order to avoid the possibility of campaigns falling under the control of a central power. The rise and consolidation of these networks of activist groups and organizations, led by values such as responsibility and involvement, is a defining characteristic of modern society.

\section{Conclusions}

As we have seen with Fuchs, while advancing a strong criticism of the political economy of consumption, he seems to recognize in commons based prosumerism a possible solution for the distortions of the capitalist system.

A commons based prosumerism may arise from the use of social media to promote civic engagement, and to build relationships based on specific interests and mutual trust, through a process in which citizenship is activated in actions of mutual support. Examples of groups of cohesive citizens, ready and able to mobilize in support of social causes, are numerous both on the web and in public spaces, both globally and locally. They generate grassroots movements that use the web and social media platforms as a sounding board and are increasingly visible. The result is empowerment of citizens from different cultures, who find in the Web an inclusive and participatory space in which to express themselves by sharing ideals and interests. The Internet has become a setting for citizenship, providing an opportunity to observe events that happen in the world in a critical tone, and a setting for the empowerment of citizens, understood as communicative empowerment. Important examples are the initial Occupy Wall Street, then Occupy the World, or the NO-TAV movement of the Susa Valley [37]. 
For Jenkins, this participatory culture occurs when the more experienced participants share knowledge with others, by entering into contact with others.

In contrast, critics of this proactive view of commons based prosumerism tend to define it as slacktivism, or armchair activism: those forms of protest that are generated in the network and which are not supported by a real and active participation in what is commonly considered life offline.

The increasing use of the tools provided by new technologies has lead to the diffusion of social media, not only in private life but also in the public sector. This has resulted in a shift in the balance of hierarchical relations and has provided new forms of democratic participation at every level. According to Maiaccio [38], "information explosion... refers to the need and the opportunity to examine the subjective iterative content of the expert planning process: a maximum level of interaction in the new plans surprisingly seems to correspond to a maximum level of personal involvement and self-reflection".

In our opinion, this interpretation is based on a dichotomy that no longer exists, i.e., the distinction between online and offline. The effects of online and offline behavior now have opposing consequences and repercussions. According to Jurgenson [39], contemporary society has overcome the distinction between real and virtual in favor of the concept of augmented reality, in which the possibilities offered by digital technology are an expression of a continuum between real and virtual: i.e., the result of different levels of technological mediation, but not of reality. The use of Social Media represents an important variable in creating the best conditions for the coming together of the real and the virtual, but it is not the only one. The development and maintenance of community interests through digital media enhance and amplify the opportunities offered by face-to-face interactions. The value of the skills and knowledge of micro-communities in the wider community enhance the flow of communication and information when their interaction is facilitated through digital tools. Real and virtual therefore represent a continuum in which the so-called virtual is just an enhancement of the opportunities offered by the real [40]. In particular, the dimensions of communication, participation, empowerment, and production of meaning converge in favor of a process of "performative participation" or "remix culture" [41], in which the collective action of prosumerism, in its digital and/or material forms, generates diverse behaviors that imbue the mechanisms of participation and citizenship with new meaning and significance.

\section{References}

1. Toffler, A. The Third Wave, 1st ed.; Bantam Books: New York, NY, USA, 1980.

2. Ritzer, G.; Jurgenson, N. Production, consumption, prosumption: The nature of capitalism in the age of the digital "prosumer". J. Consum. Cult. 2010, 10, 13-16.

3. Baudrillard, J. The Consumer Society: Myths and Structures; SAGE Publication Ltd.: London, UK, 1970.

4. Eco, U. Apocalittici e Integrati: Comunicazioni di Massa e Teorie Della Cultura di Massa (in Italian); Bompiani: Milan, Italy, 1964.

5. Douglas, M.; Isherwood, B. The World of Goods-Towards an Anthropology of Consumption; Basic Books: New York, NY, USA, 1979.

6. Miller, D. A Theory of Shopping; Cornell University Press: New York, NY, USA, 1998. 
7. McCracken, G. Culture and Consumption: New Approaches to the Symbolic Character of the Consumer Good and Activities; Indiana University Press: Bloomington, IN, USA, 1988.

8. Silverstone, L. Consuming Technologies: Media and Information in Domestic Spaces; Routledge: London, UK, 1992.

9. Campbell, C. The craft consumer culture, craft and consumption in a postmodern society. J. Consum. Cult. 2005, 5, 23-45.

10. Ritzer, G. The McDonaldization of Society; SAGE Publication Ltd.: London, UK, 2011.

11. Ritzer, G. Focusing on the prosumer-On correcting an error in the history of social theory. In Prosumer Revisited; VS Verlag: Wiesbaden, Germany, 2010.

12. Kopytoff, I. The cultural biography of things: Commoditization as process. In The Social Life of Things-Commodities in Cultural Perspective; Appadurai, A., Ed.; Cambridge University Press: Cambridge, UK, 1986; pp. 64-91.

13. Fuchs, C. Labor in informational capitalism and on the Internet. Inf. Soc. 2010, 26, 179-196.

14. Rey, P.J. Alienation, exploitation, and social media. Am. Behav. Sci. 2012, 56, 399-420.

15. Cova, B.; White, T. Counter-brand and alter-brand communities: The impact of Web 2.0 on tribal marketing approaches. J. Mark. Manag. 2010, 26, 256-270.

16. Bartoletti, R.; Paltrinieri, P. Consumo e prosuemrismo in rete: processi di creazione di valore (in Italian). Sociolog. Comun. 2012, 43, 7-14.

17. Bourdieu, P.; Wacquant, L. An Invitation to Reflexive Sociology; The University of Chicago Press: Chicago, IL, USA, 1992.

18. Field, J. Social Capital; Routeledge: London, UK, 2003.

19. Granovetter, M.S. The strenghth of weak ties. Am. J. Sociol. 1973, 78, 1360-1380.

20. Burt, R.S. Brokerage and Closure. An Itrodiction to Social Capital; Oxford University Press: Oxford, UK, 2005.

21. Lin, N. Building a network theory of social capital. Connections 1999, 22, 28-51. Available online: http://www.insna.org/PDF/Connections/v22/1999_I-1-4.pdf (accessed on 6 January 2013).

22. Bickner, C. Down by Law. A List Apart, 6 April 2011, No. 104; Available online: http://www.alistapart.com/articles/downbylaw (accessed on 6 January 2013).

23. Wilson, E.J. The Information Revolution and Developing Countries; MIT Press: Cambridge, MA, USA, 2004.

24. Katz, A.E.; Rice, R.E. Social Consequences of Internet Use; MIT Press: Cambridge, MA, USA, 2002.

25. Putnam, R.D. Bowling Alone: The Collapse and Revival of American Community; Simon \& Schuster: New York, NY, USA, 2000.

26. Williams, D. On and off the "net": Scales for social capital in an online era. J. Comput.-Mediat. Commun. 2006, 11, 593-628.

27. Fukuyama, F. The End of History and the Last Man; Avon Books Inc.: New York, NY, USA, 1992.

28. Putnam, R., Making Democracy Work, Civic Traditions in Modern Italy; Princeton University Press: Princeton, NJ, USA, 1993.

29. Boyd, D.M.; Ellison, N. Social network sites: Definition, history, and scholarship. J. Comput.-Mediat. Commun. 2007, 13, 210-230.

30. Steinfield, C.; Ellison, N.B.; Lampe, C. Social capital, self-esteem, and use of online social network sites: A longitudinal analysis. J. Appl. Dev. Psychol. 2008, 29, 434-445. 
31. Donath, J.S.; Boyd, D. Public displays of connection. BT Technol. J. 2004, 22, 71-82.

32. Micheletti, M.; Føllesdal, A.; Stolle, D. Politics, Products, and Markets: Exploring Political Consumerism Past and Present; Transacrion Publishers: New Brunswick, NJ, USA, 2004.

33. Scammell, M. Designer Politics: How Elections Are Won; St. Martin's Press: New York, NY, USA, 1995.

34. Bennett, W.L. Branded Political Communication, in Politics, Products, and Markets: Exploring Political Consumerism Past and Present; Micheletti, M., Føllesdal, A., Stolle, D., Eds.; Transacrion Publishers: New Brunswick, NJ, USA, 2004.

35. Scammell, M. The Internet and civic engagement: The age of the citizen consumer. Polit. Commun. 2000, 17, 351-355.

36. Blumler, J.; Kavanagh, D. The third age of political communication: Influences and feature. Polit. Commun. 1999, 16, 209-230.

37. Degli Esposti, P. Green marketing 2.0: A change of paradigm. In Green Marketing Hanbook. Methods, Tools and Practices; Cavallo, M., Degli Esposti, P., Konstantinu, K., Eds.; Franco Angeli Editore: Milan, Italy, 2012.

38. Maciocco, G. Lacittà, la Mente, il Piano: Sistemi Intelligenti e Pianificazione Urbana (in Italian); Franco Angeli Editore: Milan, Italy, 1994.

39. Jurgenson, N. Digital Dualism versus Augmented Reality. Available online: http://thesocietypages.org/cyborgology/tag/slaktivism/ (accessed on 6 January 2013).

40. Jenkins, H. Convergence culture. Where New and Old Media Collide; New York University Press: New York, NY, USA, 2006.

41. Lessig, L. Remix: Making Art and Commerce Thrive in the Hybrid Economy; Penguin Press: London, UK, 2008.

(C) 2013 by the authors; licensee MDPI, Basel, Switzerland. This article is an open access article distributed under the terms and conditions of the Creative Commons Attribution license (http://creativecommons.org/licenses/by/3.0/). 